\title{
Tropical Cyclone-Induced Upper-Ocean Mixing and Climate: Application to Equable Climates
}

\author{
Robert L. Korty,* Kerry A. Emanuel, and JefFery R. ScotT \\ Program in Atmospheres, Oceans, and Climate, Massachusetts Institute of Technology, Cambridge, Massachusetts
}

(Manuscript received 30 August 2006, in final form 16 May 2007)

\begin{abstract}
Tropical cyclones instigate an isolated blast of vigorous mixing in the upper tropical oceans, stirring warm surface water with cooler water in the thermocline. Previous work suggests that the frequency, intensity, and lifetime of these storms may be functions of the climate state, implying that transient tropical mixing could have been stronger during warmer equable climates with higher concentrations of carbon dioxide. Stronger mixing of the tropical oceans can force the oceans' meridional heat flux to increase, cooling tropical latitudes while warming higher ones. This response differs significantly from previous modeling studies of equable climates that used static mixing; coupling mixing to climate changes the dynamic response. A parameterization of mixing from tropical cyclones is developed, and including it leads to a cooling of tropical oceans and a warming of subtropical waters compared with control cases with fixed mixing. The mixing penetration depth regulates the magnitude of the response.
\end{abstract}

\section{Introduction}

Around the rim of the Arctic Ocean, fossilized remains of ancient conifer forests, plants, and animals intolerant of frost lie scattered across the barren tundra (e.g., Dawson et al. 1976; Schweitzer 1980; McKenna 1980; Eberle and Storer 1999). During the PaleoceneEocene thermal maximum $\sim 55$ million years (Myr) ago Arctic sea surface temperatures (SSTs) may have exceeded $20^{\circ} \mathrm{C}$ (Sluijs et al. 2006), and above-freezing temperatures at polar latitudes were common through a significant fraction of the Phanerozoic eon (see Huber et al. 2000). Contemporaneous tropical temperatures varied less but were warmer than today during the warm periods of the Late Cretaceous and early Cenozoic era (Pearson et al. 2001; Tripati et al. 2003). ${ }^{1}$ Taken

\footnotetext{
${ }^{1}$ The Phanerozoic eon covers the most recent $540 \mathrm{Myr}$ of earth history. The Cenozoic era began at the conclusion of the Cretaceous $65 \mathrm{Myr}$, and the Paleocene (65-55 Myr) and Eocene (55-34 Myr) were the first two epochs of this era.

* Current affiliation: Department of Atmospheric Sciences, Texas A\&M University, College Station, Texas.

Corresponding author address: Robert L. Korty, Department of Atmospheric Sciences, Texas A\&M University, 3150 TAMU, College Station, TX 77483-3150.

E-mail: korty@alum.mit.edu
}

DOI: $10.1175 / 2007 J C L I 1659.1$

(C) 2008 American Meteorological Society together, there is persuasive evidence that the surface meridional temperature gradient was weak during these warm, equable climates. The evidence of weak gradients has presented a challenging problem for dynamicists: the intensity of the atmospheric baroclinic eddies, which are principally responsible for transporting enthalpy poleward in the present climate, itself varies monotonically with the surface temperature gradient (e.g., Stone and Miller 1980). When the meridional temperature gradient is weak, it is unclear what mechanisms would be able to provide the strong heat fluxes needed to maintain a weak surface gradient. Given the strong evidence for a weak planetary-scale meridional temperature gradient and the inability of any obvious mechanism to provide sufficient heat fluxes to maintain it, equable climates have posed a paradox for climate researchers. Several hypotheses have been proposed to address this. These include radiative forcing from high concentrations of carbon dioxide $\left(\mathrm{CO}_{2}\right.$; Barron and Washington 1985), strong ocean heat transport (Barron 1983; Emanuel 2002; Korty 2005), polar stratospheric clouds (Sloan et al. 1992; Kirk-Davidoff et al. 2002), and extratropical convection (Abbot and Tziperman 2008). $\mathrm{CO}_{2}$ has varied through the Phanerozoic eon, with higher concentrations often found during times when the earth was ice free (Crowley 2000), but supplying climate models with enough $\mathrm{CO}_{2}$ to maintain above-freezing temperatures at the poles produces tropical temperatures that exceed 
those derived from proxy evidence (e.g., Sloan and Rea 1996). While the more recent estimates of warmer tropical temperatures (Pearson et al. 2001; Tripati et al. 2003) have reduced the disagreement with models, some discrepancy remains. Explaining weak pole-toequator temperature gradients has proved to be a vexing problem.

Many of the above studies have focused on mechanisms that keep polar temperatures warm, but another possibility is that higher levels of $\mathrm{CO}_{2}$ coupled with a mechanism to cool the tropics. Emanuel (2001) first proposed that the mixing induced by tropical cyclones might drive a substantial portion of the oceans' observed heat flux. Tropical cyclones induce vigorous mixing of warm, surface layer water with colder, denser water from the upper thermocline. This mixing leads to the spectacular reductions of SSTs observed in the wake of tropical cyclones (Leipper 1967; Price 1981) and simultaneously mixes heat down the water column. The recovery of these wakes is complicated, but Emanuel (2001) has shown that the warm anomalies left at depth may persist long after the surface temperatures have recovered, which entails a net heating of the ocean. In equilibrium, much of this warm anomaly could be transported out of the tropics and given up to the atmosphere at higher latitudes.

While much of the literature has focused on the magnitude and role of abyssal mixing (see review paper by Wunsch and Ferrari 2004), work by Scott and Marotzke (2002), Boccaletti et al. (2005), Korty (2005), and Bugnion et al. (2006) has shown that the oceans' heat flux can be affected by mixing confined to the upper ocean alone. Mixing induced by tropical cyclones is confined to the upper water column, although internal waves generated by the passage of a storm propagate into the ocean interior (Price 1983); these waves may carry a significant amount of energy into the interior locally (Nilsson 1995). Calculations using the observed record of tropical cyclones indicate that the amount of net column heating required to restore the cold surface wakes left by these storms is on the order of the oceans' poleward heat flux (Emanuel 2001), rendering this a potentially important interaction. But the uncertainties associated with such calculations are large, making conclusive evidence for a dominant role elusive. Direct measurements of the tropical thermocline have revealed that little mixing occurs there in the present climate (e.g., Gregg 1987), but more recent measurements have found that mixing may be nearly nonexistent when the wind stress is too weak to push the local Richardson number below a critical value (Raymond et al. 2004). This suggests that mixing in the tropical thermocline is a highly transient event, and it leaves open the possibility that more mixing occurs here episodically than has been observed directly. ${ }^{2}$ There remains considerable uncertainty regarding the role of tropical cyclones in ocean dynamics in the present climate, but it is clear that the mixing they induce occurs where ocean models are most sensitive to it-the tropical thermocline (Scott and Marotzke 2002; Bugnion et al. 2006). A consequence of this is that if tropical cyclones were more frequent, stronger, and longer lasting in past warm climates, their cumulative impact on the oceans was likely more substantial than it is today.

In this paper, we investigate whether tropical cyclones could have supplied sufficient mixing to the upper tropical oceans to cool tropical temperatures and drive a stronger poleward heat flux in the oceans during warm climates. Our goal is to present evidence that this mixing, in concert with elevated radiative forcing, could make a substantial contribution to the poleward transport of heat in the oceans during warm climates and weaken the surface meridional temperature gradient. This is a conceptual paper, and our objective is not to model in detail any particular equable climate; thus, continental geography, although an important variable on tectonic time scales (e.g., Crowley 2000), is kept in its present-day configuration in all of our simulations. Here we wish to explore some of the consequences of allowing upper tropical ocean mixing to vary with the climate state. We begin by reviewing the coupled model of intermediate complexity used in this study and presenting our control cases, which used imposed, fixed mixing. We next demonstrate that if mixing in the upper tropical oceans is elevated in warm climates, the ocean heat flux can respond in interesting ways. We then derive a parameterization that couples the amount of mixing in the upper tropical oceans to the potential intensity of tropical cyclones. We discuss how these interactions could be stronger if accompanied by changes in thermocline stratification during warm climates.

\section{Coupled model}

To explore these questions, we use a coupled model of intermediate complexity. Dutkiewicz et al. (2005) documented the version used here: a three-dimensional

\footnotetext{
${ }^{2}$ Tracer studies removed most lingering doubt about the representativeness of microstructure measurements, which are a snapshot in space and time. Ledwell et al. (1998) studied the evolution of a dye injected in the eastern subtropical Atlantic over the course of $2 \mathrm{yr}$ (1992-94), by which point it had spread west to $55^{\circ} \mathrm{W}$; they inferred that the diapycnal diffusion was $O\left(10^{-5}\right)$ $\mathrm{m}^{2} \mathrm{~s}^{-1}$ in the upper ocean. There were, however, no tropical cyclones during 1992-94 in this region of the Atlantic, and none formed in the Brazil basin, where dye was released in a separate experiment (Ledwell et al. 2000).
} 
ocean model, the Massachusetts Institute of Technology (MIT) general circulation model (Marshall et al. 1997a,b), coupled to a zonal-mean atmospheric model described by Sokolov and Stone (1998). The ocean model grid is $4^{\circ}$ latitude $\times 4^{\circ}$ longitude with 15 vertical levels and realistic topography. The atmosphere model has 11 vertical levels and $4^{\circ}$ latitude resolution; it uses the parameterizations of heat, moisture, and momentum transports by large-scale eddies developed by Stone and Yao $(1987,1990)$.

The advantage of this construction is that coupled experiments can be run efficiently while using an ocean model detailed enough to examine mechanisms and feedbacks that are essential for understanding changes in the ocean circulation. Thus, we are able to run a modest number of experiments to equilibrium to test some parameterizations of ocean mixing that are functions of tropical climate. A limitation of this approach is the need to use flux adjustments or anomaly coupling. While some of the most recent climate models no longer require such adjustments (e.g., Collins et al. 2006), they retain slow drifts in the deep ocean temperature; often, these are slow enough to ignore for global warming experiments. Many other models cannot simulate present-day conditions without adjustments (e.g., Opsteegh et al. 1998; Goosse et al. 2001).

The coupled model is spun up with radiative forcings for 1980 when $\mathrm{CO}_{2}$ concentration was 338 ppm. During this phase, the wind stresses and air-sea freshwater fluxes used to force the ocean model were taken from monthly mean observations; SSTs were relaxed back to observations during the spinup phase. The atmospheric model calculates the surface winds and temperatures in addition to the precipitation, evaporation, and river runoff but stores these data for the end of the spinup. After running for $1500 \mathrm{yr}$ in this mode, we calculate the heat and freshwater fluxes and surface wind adjustments necessary to bring the information passed from the atmosphere to the ocean to the same magnitude as observations. These flux adjustments can be thought of as model deficiency; such corrections must be applied to reproduce the current climate where the forcing is known.

The model is then run in coupled mode using contemporary forcings for $1000 \mathrm{yr}$ to verify its stability (i.e., no drifts in circulation, temperature, or salinity). Additionally, a coupled simulation using high loads of $\mathrm{CO}_{2}$ (a factor of 10 larger than 1980 values) is run to equilibrium to assess how the model behaves in very warm climates. As noted earlier, while $\mathrm{CO}_{2}$ may have reached (or exceeded) these levels during earlier parts of the Phanerozoic eon (Crowley 2000), this is not meant to correspond to any specific period; many other factors surely influenced the details of those paleoclimates. Additional detail about the coupling procedure can be found in Dutkiewicz et al. (2005); these techniques are the same as those used by Kamenkovich et al. (2002) in an earlier version of the model.

\section{Control case: Fixed mixing}

Before exploring the effects of mixing parameterizations that respond to tropical cyclone activity, we demonstrate the behavior of the model when mixing is uniform and fixed. Many global climate models treat ocean mixing as static, although there is little reason to suspect this is correct (e.g., see Munk and Wunsch 1998). Lyle (1997) and Nilsson et al. (2003) have demonstrated the interesting behavior exhibited by models when the energy available to mixing (rather than the mixing itself) is held fixed, which allows mixing to evolve with changes in the stratification. ${ }^{3}$

Even with static mixing, we lack a clear understanding of how the oceans' circulation and heat transport will respond to changes in atmospheric concentrations of $\mathrm{CO}_{2}$. A comparison of coupled climate models shows a large spread in the ocean response to a quadrupling of $\mathrm{CO}_{2}$ in $140 \mathrm{yr}$, with a decline in the meridional overturning circulation ranging from $10 \%$ to $50 \%$ (Gregory et al. 2005). The equilibrium response to a large increase in $\mathrm{CO}_{2}$ has been examined in relatively few studies, but here too the results are not conclusive, ranging from little change (Stouffer and Manabe 2003) to increased overturning strength (Wiebe and Weaver 1999). In short, these studies suggest that even with fixed mixing, the response seems model dependent and not well understood.

In Figs. $1 \mathrm{a}$ and $1 \mathrm{~b}$, the results from a simulation forced with contemporary amounts of $\mathrm{CO}_{2}$ (338 ppm) and uniform diapycnal diffusivity ( $\kappa$ is $0.1 \mathrm{~cm}^{2} \mathrm{~s}^{-1}$ ) are presented. (All data are an average over the final century of the fully coupled simulations.) Note that a deep circulation travels northward in the upper kilometer of the Atlantic Ocean, sinks, and returns southward at depth. Some of this deep water is upwelled in the Atlantic, but much of it flows out of the basin and returns to the surface in the Pacific, Indian, or Southern Ocean $\left[\sim 9-\mathrm{Sv}\left(1 \mathrm{~Sv} \equiv 10^{6} \mathrm{~m}^{3} \mathrm{~s}^{-1}\right)\right.$ flow across $30^{\circ} \mathrm{S}$ in the Atlantic for the simulation of the present climate]. The dominant features of the Pacific (Fig. 1b) are the sur-

\footnotetext{
${ }^{3}$ On the other hand, B. Marzeion (2007, personal communication) suggest their results might not hold in a more realistic, global model. Lyle (1997) and Nilsson et al. (2003) were idealized studies using single hemisphere models.
} 
(a) Atlantic

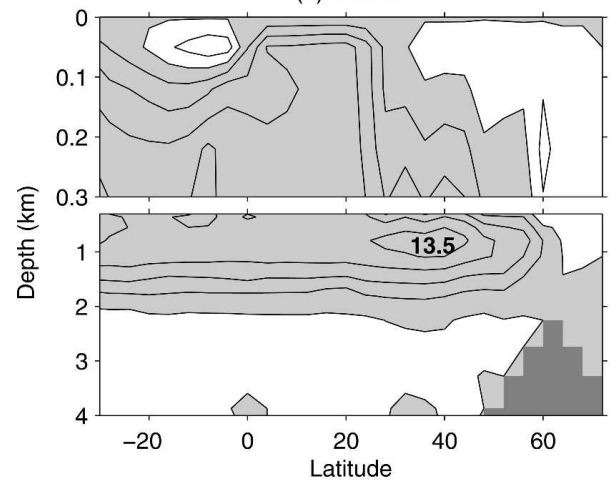

(c) Atlantic

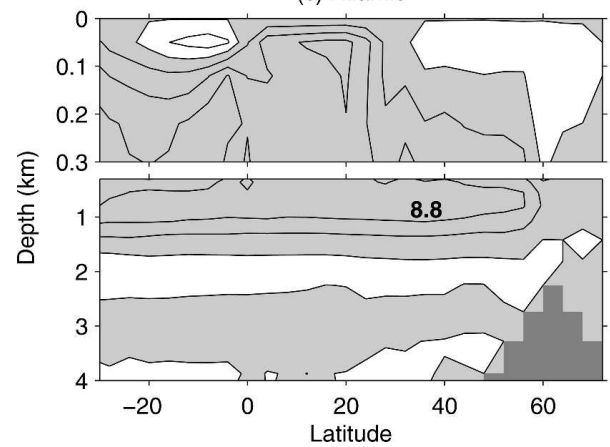

(b) Pacific

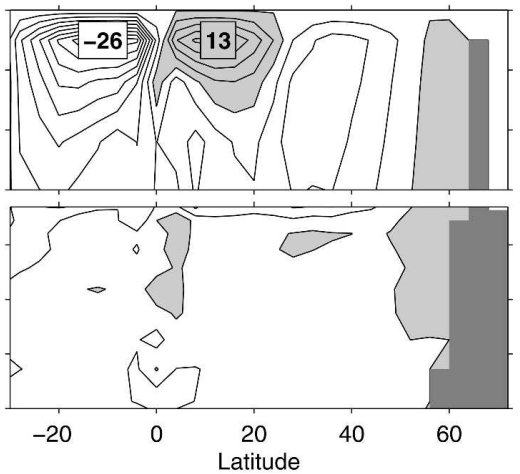

(d) Pacific
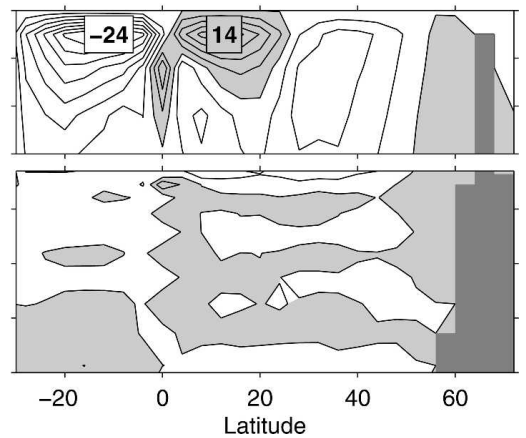

FIG. 1. The circulation in the meridional plane of the (a) Atlantic and (b) Pacific north of $30^{\circ} \mathrm{N}$ for a simulation with uniform mixing and 338- $\mathrm{ppm} \mathrm{CO}_{2}$. (c), (d) As in (a), (b) but for a simulation with fixed mixing and 3380-ppm $\mathrm{CO}_{2}$. In all panels, contours are drawn every $3 \mathrm{~Sv}$ and positive values (circulating clockwise) are shaded in light gray; local extrema are written in boldface text (Sv). The top $300 \mathrm{~m}$ are magnified.

face Ekman cells in the upper ocean; observations show much of the ocean heat flux is carried here in the present-day ocean (Haidvogel and Bryan 1992). When $\mathrm{CO}_{2}$ is increased to $3380 \mathrm{ppm}$, temperatures warm and the oceans' meridional heat flux decreases slightly (see Fig. 2).

High $\mathrm{CO}_{2}$ warms the surface of the oceans everywhere, but the warming is amplified at higher latitudes in the northern Pacific and in the Norwegian and Barents Seas (not shown). Combined with a freshening of surface waters at these northern latitudes, the meridional buoyancy gradient decreased. Figures $1 \mathrm{c}$ and $1 \mathrm{~d}$ show the circulation for this high $\mathrm{CO}_{2}$ experiment; in many respects these panels are similar to the one with 338 ppm $\mathrm{CO}_{2}$, but the meridional overturning in the Atlantic has decreased in intensity. The surface wind forcing is largely similar between the two experiments.

The high $\mathrm{CO}_{2}$ levels forced a surface warming and reduction of the meridional density gradient, and the poleward ocean heat flux decreased in this experiment. Many studies have found that elevated $\mathrm{CO}_{2}$ is insufficient, by itself, to reduce the planetary temperature gradient to the low gradients found during equable cli-

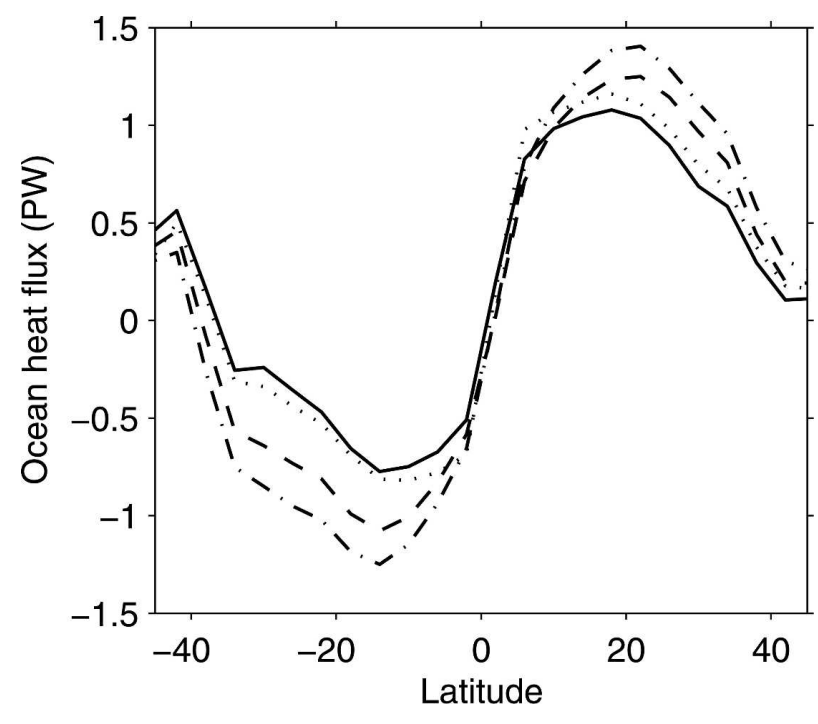

FIG. 2. Total ocean heat fluxes for simulations with uniformly weak mixing and 338-ppm $\mathrm{CO}_{2}$ (dotted), uniformly weak mixing and 3380-ppm $\mathrm{CO}_{2}$ (solid), elevated tropical mixing to $220 \mathrm{~m}$ and 3380-ppm $\mathrm{CO}_{2}$ (dashed), and elevated tropical mixing to $360 \mathrm{~m}$ and 3380-ppm $\mathrm{CO}_{2}$ (dashed-dotted). 


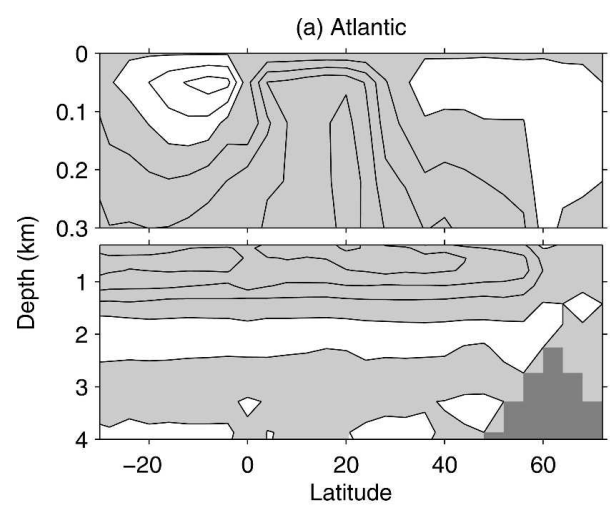

(c) Atlantic

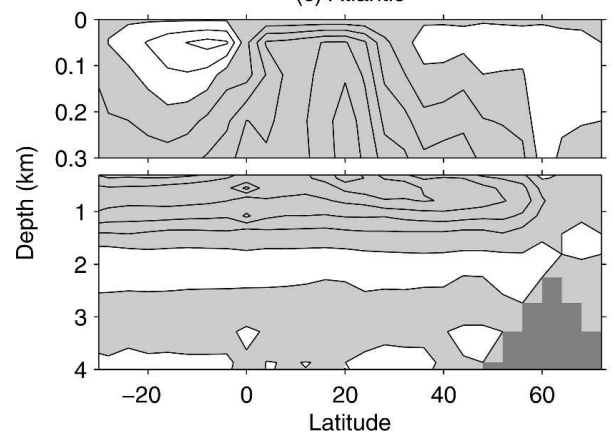

(b) Pacific

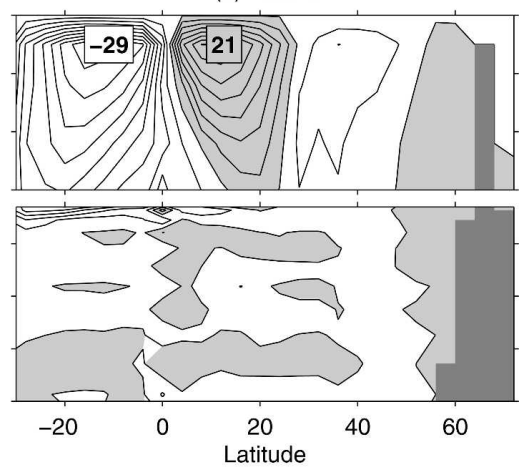

(d) Pacific

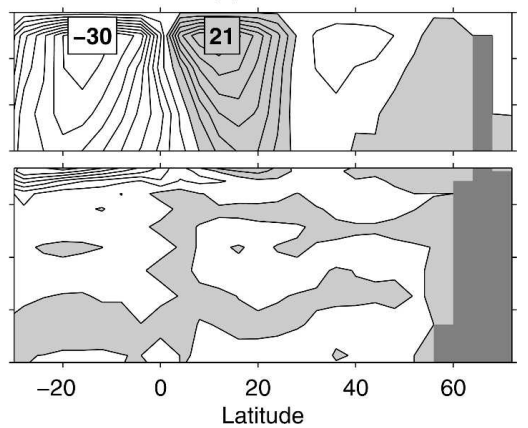

FIG. 3. As in Fig. 1 but for simulations with 3380-ppm $\mathrm{CO}_{2}$ and a diffusivity of $1.0 \mathrm{~cm}^{2} \mathrm{~s}^{-1}$ down to (a), (b) 220 or (c), (d) $360 \mathrm{~m}$.

mates (e.g., Barron and Washington 1985; Sloan and Rea 1996; Shellito et al. 2003). But what if warmer climates were accompanied by increased mixing in the oceans? Tropical cyclones provide an isolated but intense blast of mixing along their tracks; if the frequency, intensity, and lifetime of these storms increase with temperature, mixing in the upper tropical oceans should vary accordingly. This simple coupling can dramatically alter the response of the warm climate simulations.

\section{Elevated upper-ocean mixing}

We first show that elevating mixing in the upper tropical oceans can have a significant impact on the oceans' poleward heat flux. We ran additional experiments with 3380 ppm $\mathrm{CO}_{2}$, but the diffusion coefficient equatorward of $30^{\circ}$ latitude was arbitrarily increased to $1 \mathrm{~cm}^{2} \mathrm{~s}^{-1}$ in the upper part of the water column. In one, mixing in the tropics was elevated in the top three model levels, which occupy the uppermost $220 \mathrm{~m}$; in another, mixing in the tropics was elevated through the top four boxes, to a depth of $360 \mathrm{~m}$. Figure 3 shows the circulation for these two simulations. In both cases, heat gained at the surface is diffused down the water column, and, compared to the case with uniform mixing
(Figs. 1c,d), the wind-induced Ekman cells in the upper part of the oceans intensified and deepened. (Many of the contours for the Pacific Ekman cells now reach to 300-m depth.)

The heat fluxes have changed substantially, as shown in Fig. 2. Compared to the run with 3380 ppm $\mathrm{CO}_{2}$ and uniformly weak mixing, the peak value of the oceanic poleward heat flux in the Northern Hemisphere increases $16 \%$ when mixing is elevated to $220 \mathrm{~m}$; the peak Southern Hemisphere value increases 40\%. Adding higher mixing down to $360 \mathrm{~m}$ increases the peak of the poleward heat fluxes by $30 \%$ in the Northern Hemisphere and $62 \%$ in the Southern Hemisphere. This finding is consistent with the earlier work of Boccaletti et al. (2005), who showed that the bulk of the oceans' heat flux is carried in the top $500 \mathrm{~m}$. The key result is that when higher loads of $\mathrm{CO}_{2}$ are accompanied by elevated mixing through the upper tropical oceans, the stronger mixing can alter the way the heat fluxes change from the present climate.

This mixing has a twofold impact on the latitudinal distribution of SSTs. The principal effect of tropical cyclone mixing is to lift cold, dense, thermocline water to the surface, where it is heated by surface fluxes. Second, enthalpy mixed into the interior will increase the oceans' heat content (Pasquero and Emanuel 2008), 
(a)

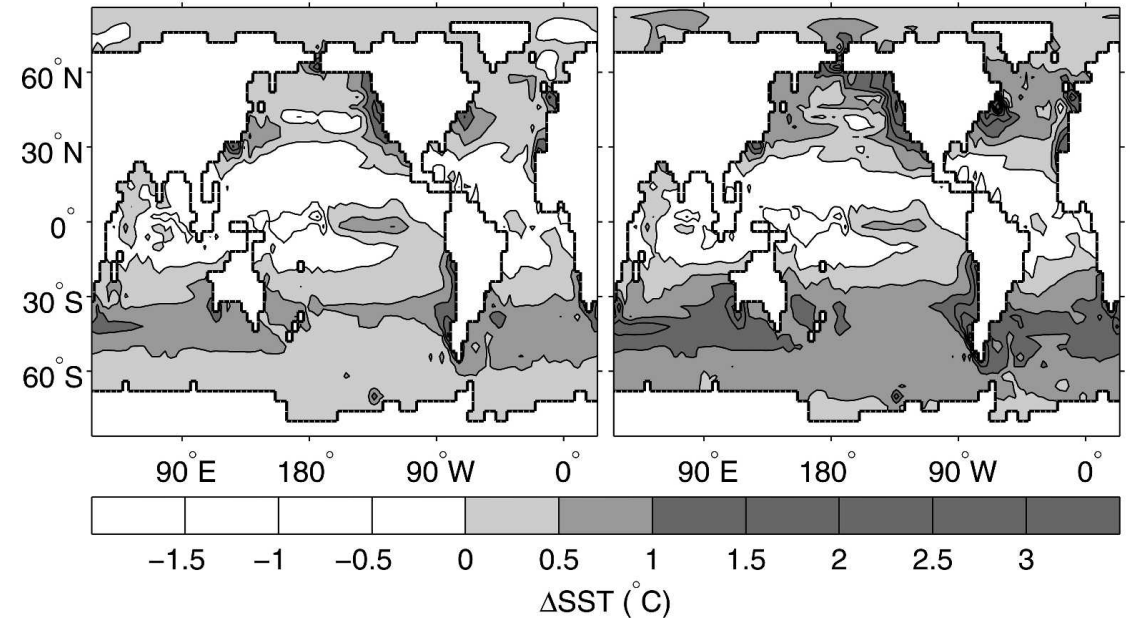

(c)

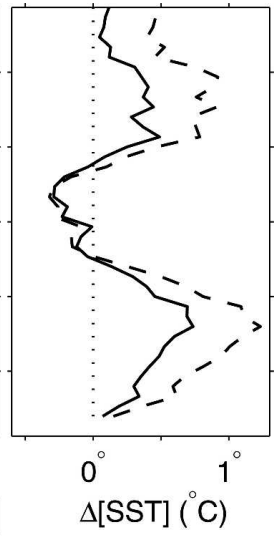

FIG. 4. Change in SSTs for runs with 3380-ppm $\mathrm{CO}_{2}$ between (a) a simulation with elevated tropical mixing to $220 \mathrm{~m}$ and the control (uniformly weak mixing) and (b) a simulation with elevated tropical mixing to $360 \mathrm{~m}$ and the control. (c) Change in zonally averaged SST for the simulations shown in panels (a) (solid) and (b) (dashed).

but in equilibrium much of this could be advected out of the tropics. The increased heat transport shown in Fig. 2 leads to a reduction of tropical temperatures and an increase in midlatitude ones, as can be seen in Fig. 4. Qualitatively, this near-surface tropical mixing narrows the gap between proxy data and model results: if the atmosphere was loaded with high levels of $\mathrm{CO}_{2}$ and tropical mixing increased, the oceans could sustain a stronger poleward heat flux, which in turn limits tropical temperatures. Could changes in global tropical cyclone activity account for a change in mixing that is this large? There are two separate questions: First, by how much would increased tropical cyclone activity amplify the effective diffusion coefficient? ${ }^{4}$ Second, how deeply would tropical cyclone mixing penetrate during warmer climates? As seen in Fig. 4, this is a critical question for this interaction. We begin exploring these issues with a parameterization coupling upper tropical mixing to tropical cyclone activity, as described in the next section, and return to some issues regarding the strength and depth of this mixing in section 6 .

\section{Interactive mixing from tropical cyclones}

We now turn to the question of whether tropical cyclones could induce sufficient mixing of the upper por-

\footnotetext{
${ }^{4}$ We ran additional experiments in which the diffusion coefficient was elevated to $3.0 \mathrm{~cm}^{2} \mathrm{~s}^{-1}$ in the upper ocean, and the peak value of the heat fluxes do not differ significantly from the simulations using an upper-ocean diffusion coefficient of $1.0 \mathrm{~cm}^{2} \mathrm{~s}^{-1}$ presented in this section. It appears that once the amplitude of the diffusion coefficient reaches a sufficient level, elevating it further has little additional effect.
}

tion of the low-latitude oceans during warm, equable climates to drive stronger poleward heat fluxes. Our goal is not to simulate the details of upper-ocean mixing from individual storms, but rather to examine the cumulative effects from these transient events. This problem is challenging because the real mixing is turbulent, not diffusive, yet we wish to examine the effects on large-scale problems. Because we are after aggregate effects and a first-order understanding of how this might interact with climate, we make a number of simplifications.

Estimates of mixing inferred from measurements taken in the tropical thermocline show that the diffusion coefficient is $O(0.1) \mathrm{cm}^{2} \mathrm{~s}^{-1}$ (Gregg 1987; Wunsch and Ferrari 2004). Using diffusion coefficients of this magnitude in numerical models, however, often produces circulations believed to be too weak (e.g., Cummins et al. 1990), and thus many models require larger values to replicate the strength of the oceans' meridional overturning circulation and heat fluxes for the present climate. While it is certainly possible that these large required diffusivities might simply compensate for other model deficiencies, we postulate that the direct measurements have largely captured the nearly quiescent background and that isolated blasts of mixing from transient events could be quite important in the upper tropical oceans. Some evidence that this might be the case was offered by Raymond et al. (2004), who presented data suggesting that rather than a slow, steady mixing, the thermocline is mixed only when the winds are strong enough to drive the local Richardson number below a critical threshold, creating a shear instability. They conclude that mixing in the upper tropical 
oceans results from transient wind-driven events and that the strongest atmospheric disturbances are likely responsible for most of the mixing in the tropical thermocline.

\section{a. Magnitude of the diffusion coefficient}

Our approach requires that we first identify a sensible value for the diffusion coefficient and calculate the depth to which mixing penetrates in an individual storm. In fair weather conditions, Price and Sundermeyer (1999) investigated stratified Ekman layers and estimate that a sensible choice for the diffusion coefficient in the surface mixed layer is on the order of 1000 $\mathrm{cm}^{2} \mathrm{~s}^{-1}$. This is confined to the well-mixed region at the top of the ocean, where vigorous mixing creates a nearly isothermal layer from the sea surface to the top of the thermocline. Beneath this layer, mixing nearly vanishes in the strongly stratified thermocline (Gregg 1987). Given the nearly nonexistent mixing at these depths, some thermocline theories assume it is absent all together (e.g., Luyten et al. 1983).

When tropical cyclones pass over an ocean column, they induce vigorous mixing in the upper portion and cool the warm surface layer by entraining colder thermocline water. Measurements from within a hurricane are obviously difficult to secure, and characterizing the turbulent entrainment that occurs below a tropical cyclone with a simple diffusion coefficient is not realistic. But as we are only after the cumulative effects of such mixing, some manageable simplifications are possible. The initial thermal profile in the undisturbed ocean is radically altered by the passage of a storm. Data collected from the ocean in advance of a storm often show a shallow surface layer (anywhere from 25 to $200 \mathrm{~m}$ deep, depending on the location and time of year) in which temperatures are nearly uniform. Beneath this layer temperatures drop quickly, typically at a rate of $\sim 8^{\circ} \mathrm{C}(100 \mathrm{~m})^{-1}$ in the uppermost ocean (e.g., Schade 1994). As a storm passes overhead, the depth of the mixed layer increases owing to the entrainment of thermocline water from below, and it oscillates in the storm's wake owing to inertia-gravity waves. Temperatures are left nearly uniform to a greater depth, but the SST is lower because mixing stirred cooler waters to the top; this transition is diagrammed in Fig. 5.

Given that the initial and final profiles are known, and given that mixing occurs only on the time scale of the storm's passage, we can find the value of the thermal diffusion coefficient $\kappa$ that transforms an initial profile into a well-mixed one. In Fig. 5, the initial profile (dashed line) relaxes to the final one (solid line) by the time direct mixing from the tropical cyclone has

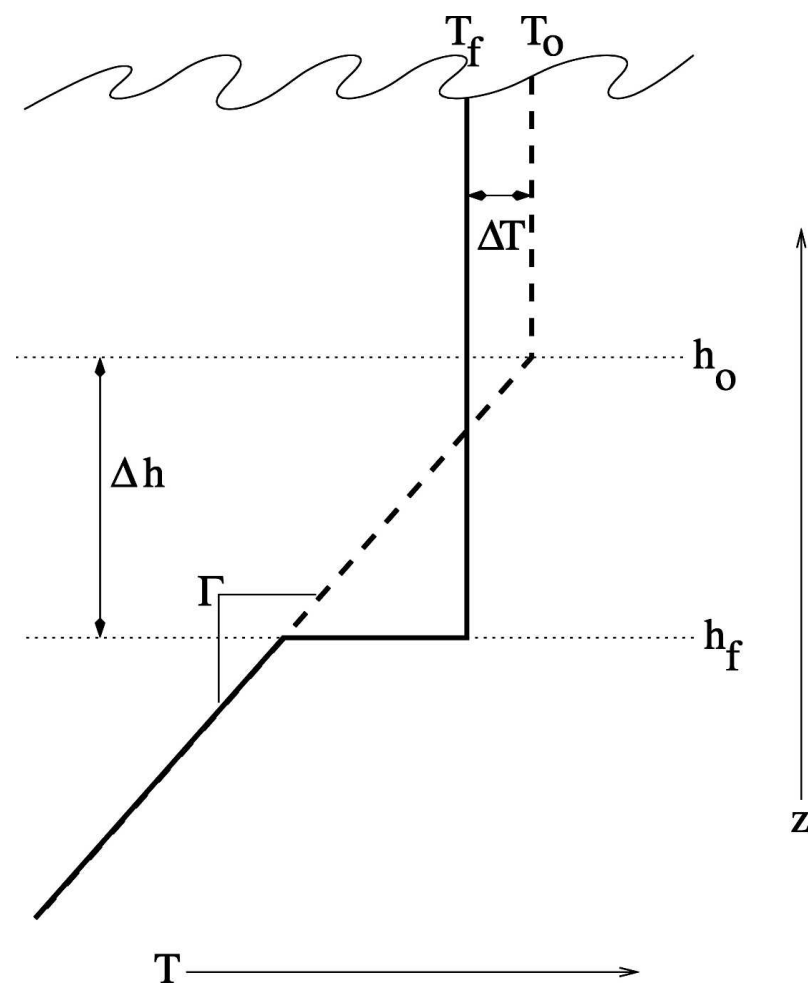

Fig. 5. Vertical temperature structure of the upper ocean before (dashed) and after (solid) the passage of a tropical cyclone.

ceased. This process can be represented by diffusion using the heat conduction equation

$$
\frac{\partial T}{\partial t}=\kappa \frac{\partial^{2} T}{\partial z^{2}} .
$$

If no-flux boundary conditions ${ }^{5}$ are imposed and an initial profile is specified, then it is straightforward to show that

$$
T(z, t)=\sum_{n=1}^{\infty} c_{n} \cos \left(\frac{n \pi z}{D}\right) e^{-\kappa(n \pi / D)^{2} t},
$$

where

$$
c_{n}=\left.\frac{2}{D} \int_{0}^{D} \cos \left(\frac{n \pi z}{D}\right) \frac{\partial T(z, 0)}{\partial z}\right|_{t=0} d z .
$$

Here $T(z, 0)$ is the initial profile, and $D$ is the depth over which the mixing occurs $\left(h_{f}\right.$ in Fig. 5). To estimate the magnitude of $\kappa$, assume that the initial profile can be represented by a single cosine wave ( $n$ is 1 ), substitute $h_{f}$ (which we take here to be $200 \mathrm{~m}$ ) for $D$, and apply an $e$-folding time scale for $t$. Given that a typical

\footnotetext{
${ }^{5}$ These are reasonable given the rapidity of the mixing.
} 


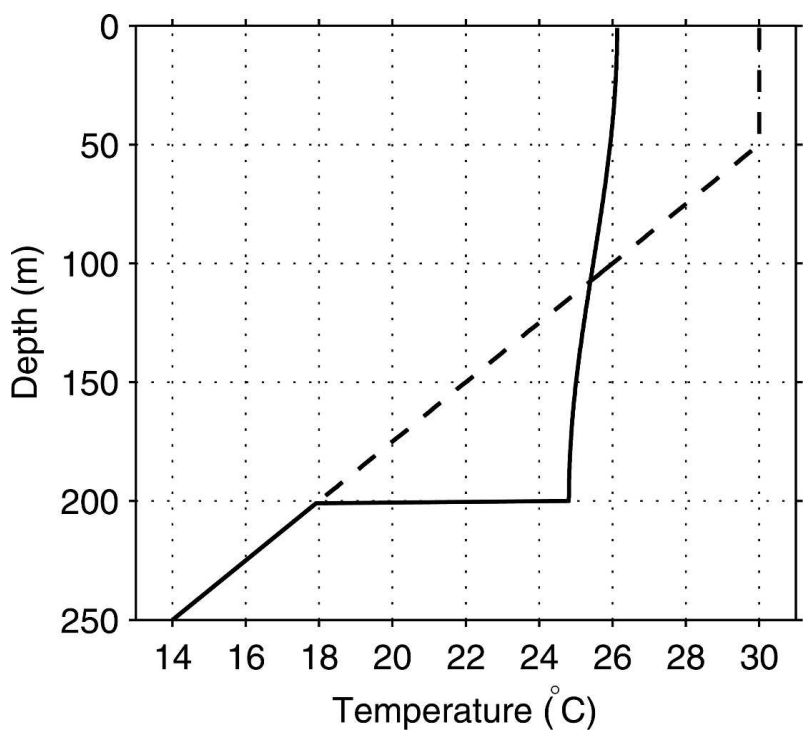

FIG. 6. Initial profile in the upper tropical ocean (dashed) and final (solid) after $12 \mathrm{~h}$ of mixing with a diffusion coefficient of $2000 \mathrm{~cm}^{2} \mathrm{~s}^{-1}$.

storm may induce intense mixing over a lateral distance of roughly $200 \mathrm{~km}$, and that a typical translation speed is roughly $5 \mathrm{~m} \mathrm{~s}^{-1}$, the initial profile must adjust to the final one within $12 \mathrm{~h}$, as intense mixing does not occur away from the core of the storm. Substituting these numbers into the exponent of (2) requires $\kappa$ to be $O\left(10^{3}\right) \mathrm{cm}^{2} \mathrm{~s}^{-1}$. This can be applied to an arbitrary initial profile, and the one shown in Fig. 6 was adjusted to the final one over $12 \mathrm{~h}$ using a value of $\kappa$ in (2) of 2000 $\mathrm{cm}^{2} \mathrm{~s}^{-1}{ }^{6}$. This value is the same order of magnitude Price and Sundermeyer (1999) estimated for the surface layer in fair weather conditions; in a storm, it is extended deeper down into the water column.

With an estimate for the diffusion coefficient in the presence of a single intense mixing event, we must now identify an appropriate temporally and spatially averaged value. We rely on the earlier work of Scott and Marotzke (2002), who showed that mixing can be concentrated in space, and of Boos et al. (2004), who showed that mixing can be isolated in time. They showed that changes in the ocean's circulation depend on variations in the spatially and temporally averaged mixing value and that concentrating mixing in infrequent or localized bursts can produce model circula-

\footnotetext{
${ }^{6}$ Note that the profile has yet to completely mix to become isothermal; bringing it nearer to this state would require another $e$-folding or two, which could be accomplished by increasing the diffusion coefficient $50 \%-100 \%$. Nevertheless, setting $\kappa$ equal to $2000 \mathrm{~cm}^{2} \mathrm{~s}^{-1}$ produces a reasonable final profile, with surface cooling of about $4^{\circ} \mathrm{C}$.
}

tions that behave as though the mixing were spread uniformly over space and in time. The spatial averaging requires great care because mixing is more important in some locations than in others; models are far more sensitive to mixing in tropical latitudes than at higher ones (Scott and Marotzke 2002; Bugnion et al. 2006). Because we are interested in an average value of mixing in regions affected by tropical cyclones, we confine the area of interest to latitudes equatorward of $30^{\circ}$.

Consider the area mixed by a single storm. The swath of ocean subjected to mixing by a tropical cyclone will scale with a cross-track length scale, $L_{y},{ }^{7}$ multiplied by the length of the track, $U_{T} \tau$, where $U_{T}$ is the translation speed and $\tau$ is the duration of the storm. The total area of the world's oceans exposed to mixing in a given year will be $\sum_{i=1}^{N}\left(L_{y} U_{T} \tau\right)$, where $N$ is the total number of storms globally. If we assume that average values for $L_{y}, U_{T}$, and $\tau$ can be applied to each individual storm, the total area mixed is

$$
A_{m}=N L_{y} U_{T} \tau
$$

The spatial average of $\kappa$ is then

$$
[\kappa]=\kappa_{\mathrm{tc}} \frac{A_{m}}{A_{t}}+\kappa_{b} \frac{A_{t}-A_{m}}{A_{t}},
$$

where $\kappa_{\mathrm{tc}}$ is the value of $\kappa$ in the presence of a tropical cyclone (estimated above to be $2000 \mathrm{~cm}^{2} \mathrm{~s}^{-1}$ ), $\kappa_{b}$ is a background, fair weather value $\left(0.1 \mathrm{~cm}^{2} \mathrm{~s}^{-1}\right), A_{t}$ is the area of the tropical oceans, ${ }^{8}$ and $A_{m}$ is determined by (4).

We now average this value in time. Each point visited by a tropical cyclone is exposed to mixing for $L_{x} / U_{T}$ seconds, where $L_{x}$ is the along-track distance over which intense mixing occurs. Then

$$
\begin{aligned}
{[\bar{\kappa}] } & =\kappa_{\mathrm{tc}} \frac{A_{m}}{A_{t}}\left(\frac{L_{x} / U_{T}}{s_{y}}\right)+\kappa_{b}\left(\frac{s_{y}-L_{x} / U_{T}}{s_{y}}\right)\left(\frac{A_{t}-A_{m}}{A_{t}}\right) \\
& =\kappa_{\mathrm{tc}} \frac{N L_{y} L_{x} \tau}{s_{y} A_{t}}+\kappa_{b}\left(\frac{s_{y}-L_{x} / U_{T}}{s_{y}}\right)\left(\frac{A_{t}-A_{m}}{A_{t}}\right) \\
& \approx \kappa_{\mathrm{tc}}\left(\frac{N L_{y} L_{x} \tau}{s_{y} A_{t}}\right)+\kappa_{b} .
\end{aligned}
$$

We take $s_{y}$ to be the number of seconds in a year so that the value of $[\bar{\kappa}]$ given by (6) is the annual and tropical

\footnotetext{
${ }^{7}$ This will be biased to the right-hand side of the track in the Northern Hemisphere, as the most intense mixing occurs on this side owing to coupling with inertial oscillations (Price 1981).

${ }^{8}$ This is approximately $(0.7) 2 \pi a^{2}$, where $2 \pi a^{2}$ is the surface area of the earth equatorward of $30^{\circ}$, and 0.7 is the fraction of this region that is ocean.
} 
spatial average of $\kappa$. We have used the facts that $A_{m} \ll A_{t}$ and $\left(L_{x} / U_{T}\right) \ll s_{y}$ to approximate (6). It is interesting that in the current climate, $N \cdot \tau / s_{y}$ is approximately 1 , though this has grown to a slightly larger value during the last few decades (e.g., Emanuel 2005). This is equivalent to having one continuous tropical cyclone somewhere in the world at all times during a given year. Substituting values of $L_{y}=L_{x} \approx 200 \mathrm{~km}$, one finds that the first term on the right-hand side of (6) is $O(0.1)$ to $O(1) \mathrm{cm}^{2} \mathrm{~s}^{-1}$ in the present climate; this represents the spatially and temporally averaged mixing from tropical cyclones in the tropics each year. This is the same magnitude calculated by Sriver and Huber (2007) and is as strong or stronger than has been observed in the tropical thermocline (e.g., Ledwell et al. 1998). Transient events, therefore, are likely to be at least as important as the background mixing that occurs in the uppermost tropical oceans. This is an important point because ocean models are particularly sensitive to mixing in these locations (e.g., Scott and Marotzke 2002; Bugnion et al. 2006), yet to date this process has been neglected.

\section{b. Depth to which tropical cyclone mixing penetrates}

Changes in SSTs and the depth of the mixed layer are directly related to the amount of thermocline water entrained into the surface layer. Considering Fig. 5, the increase in mixed layer depth $(\Delta h)$ must be related to the degree of surface cooling $(\Delta T)$. By analogy, we can construct an initial density structure, $\rho_{i}$, which is defined by the background profile. From this, $\rho_{i}\left(h_{f}\right)=$ $\rho_{o}-\Gamma \Delta h$ and $\rho_{i}\left(h_{o}\right)=\rho_{o}$, where $\Gamma$ is the thermocline lapse rate $d \rho / d z$. Models designed to study the interactions between hurricanes and the underlying ocean use turbulent closure schemes (e.g., Price 1979) to address this question (e.g., Schade and Emanuel 1999; Emanuel et al. 2004), but we use relationships between the initial and final profiles to derive a simple parameterization that can be used in large-scale models. Relating the amount of surface cooling in the final profile to the initial density structure, we derive a quartic equation for the deepening of the mixed layer $\Delta h$ which is a function of the intensity $u$ and thermocline stratification; details are contained in the appendix. The solution behaves like

$$
h_{o}+\Delta h=h_{o}+h_{*}\left(\frac{u}{u_{*}}\right)^{1.2}\left(\frac{\Gamma}{\Gamma_{*}}\right)^{-0.3},
$$

where $h_{o}$, the initial mixed layer depth $(50 \mathrm{~m}$ everywhere in all of our simulations), has been added so that (7) gives the depth below the surface to which the mixing penetrates. This predicts that the mixing depth in- creases nearly linearly with the intensity of the wind and has a somewhat weaker dependence on the stratification. Still, if climates with weak equator-to-pole temperature gradients also have weak top-to-bottom temperature differences in the ocean (hence a weaker stratification), this change could instigate a significant increase in the penetration depth.

\section{c. Model results with interactive mixing}

To test whether tropical cyclones could mix the upper tropical oceans enough to change the oceans' poleward heat transport, we constructed an experiment incorporating the dependencies derived in the previous sections. Storm mixing can vary with climate because storms' intensity, frequency, and lifetime depend on the climate state (Emanuel 2005). The intensity of individual storms will be a function of local environmental conditions (Emanuel et al. 2004), but Emanuel (2000) found that when a large enough sample is considered, observed intensities are related directly to the theoretical upper bound, the maximum potential intensity (Emanuel 1988). The potential intensity, which requires only SST and atmospheric temperature and humidity soundings for computation, can thus be used as a measure of how intensity should evolve with climate. Very little is known about what governs storm frequency, but Emanuel and Nolan (2004) show that it might grow with the third power of potential intensity. The power dissipated in the oceans, which is the dot product of the surface stress and the surface ocean currents, grows with the cube of the wind speed, assuming that the currents in the upper ocean grow linearly with the wind. Combining this with the results of Emanuel and Nolan (2004), we here first test a parameterization in which the aggregate storm mixing is a function of the sixth power of the potential intensity. Thus, a far warmer climate in which the potential intensity increases by $20 \%$ could have a threefold increase in the annually averaged diapycnal diffusion in the upper oceans.

We assume here that ocean mixing has two sources: a weak, omnipresent background value $\kappa_{b}$ and a contribution from transient tropical cyclones $\kappa_{s}$, which represents the first term in (6). Thus, the diffusion coefficient $\kappa$ will be the sum $\kappa_{b}+\kappa_{s}$. Throughout the water column in middle and high latitudes and at depth in the tropics, $\kappa_{s}$ will be 0 and the background value, which we take to be $0.1 \mathrm{~cm}^{2} \mathrm{~s}^{-1}$ [as it was in our control and consistent with observations in the present climate, e.g., Ledwell et al. (1998)], constitutes the total mixing. The storm contribution $\kappa_{s}$ scales with the potential intensity (PI) and is applied through the mixed layer $\left(h_{o}\right)$ plus $\Delta h$, the depth given by (7): 

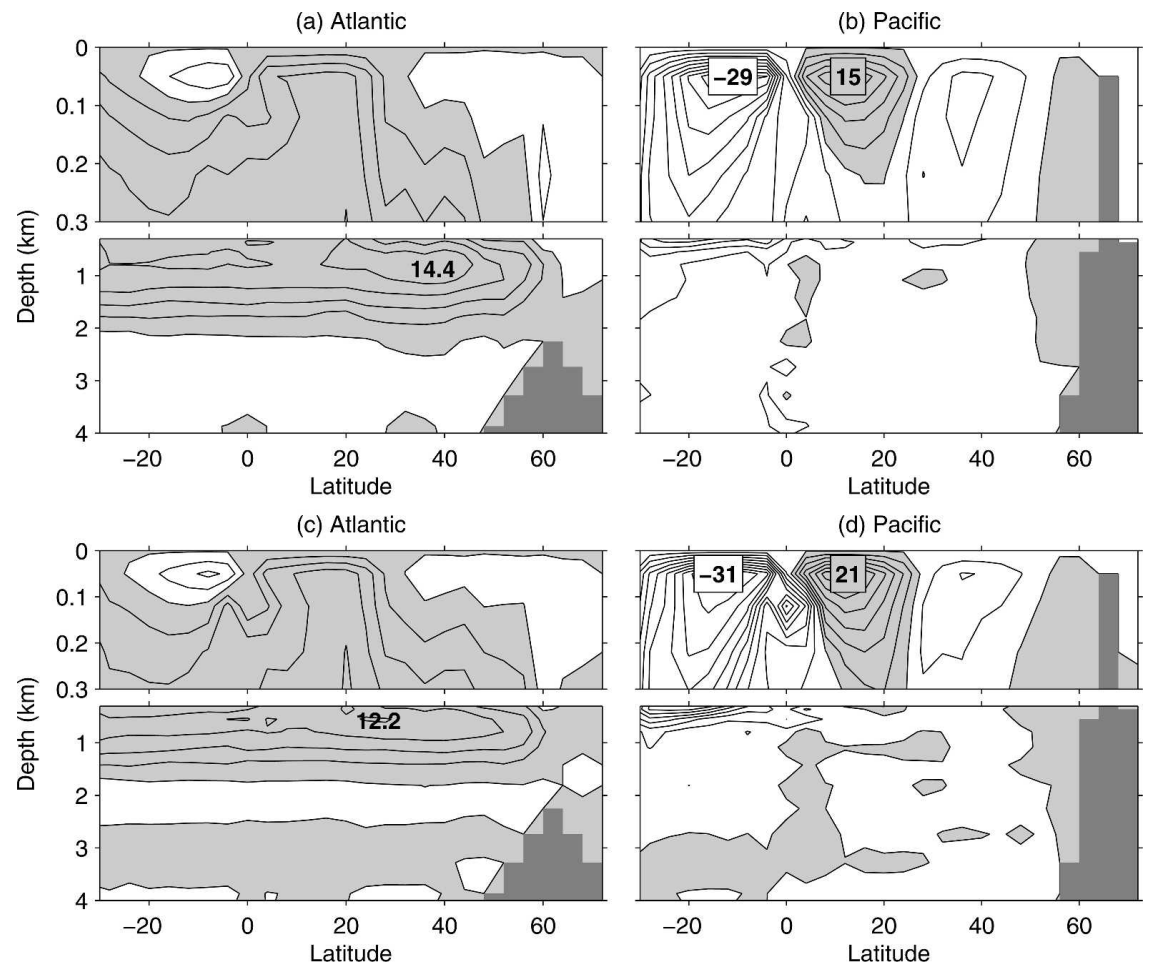

FIG. 7. As in Fig. 1 but for simulations with interactive mixing and (a), (b) 338-ppm $\mathrm{CO}_{2}$ or (c), (d) 3380-ppm $\mathrm{CO}_{2}$.

$$
\kappa_{s}(x, y)= \begin{cases}K\left[\frac{\mathrm{PI}(x, y)}{\mathrm{PI}_{*}}\right]^{6} \quad 0<z<\left(h_{o}+\Delta h\right) \text { and }|\phi| \geq 4^{\circ} \\ 0 \quad \text { everywhere else. }\end{cases}
$$

There is a great deal of sensitivity to the normalizing factors $\mathrm{PI}_{*}$ and $K$, but a thorough exploration of this lies beyond the scope of this paper. For this first test, we take $\mathrm{PI}_{*}$ to be $60 \mathrm{~m} \mathrm{~s}^{-1}$ and $K$ to be $0.1 \mathrm{~cm}^{2} \mathrm{~s}^{-1}$ (consistent with the analysis in section 5a). Using these values allows $\kappa_{s}$ to range in the present climate from less than $0.1 \mathrm{~cm}^{2} \mathrm{~s}^{-1}$ in the subtropics to a maximum of about $1 \mathrm{~cm}^{2} \mathrm{~s}^{-1}$ where the potential intensity reaches a peak value in the deep tropics of the western Pacific; these values are similar to those found by Sriver and Huber (2007). (Values of the annually averaged potential intensity for a simulation of the present climate are shown in Fig. 8a.) Because tropical cyclones are rarely observed equatorward of about $5^{\circ}$ latitude (Gray 1968), $\kappa_{s}$ is forced to be 0 in the boxes that straddle the equator.

Given that this model has discrete and coarsely spaced interfaces at which vertical diffusion is applied, we incorporate the depth dependence as follows: The top model box is $50 \mathrm{~m}$ deep and is assumed to be well mixed. The second model box extends from $50-120 \mathrm{~m}$; the third from $120-220 \mathrm{~m}$. If the depth given by (7) is between 50 and $120 \mathrm{~m}$, the amplitude of $\kappa_{s}$ applied to the 50-m interface is adjusted linearly. For example, if the mixing penetrates to $85 \mathrm{~m}$, half way through the second box, the value of $\kappa_{s}$ at the 50-m interface is half of $K\left(\mathrm{PI} / \mathrm{PI}_{*}\right)^{6}$. If the depth exceeds $120 \mathrm{~m}$ (but not 220 $\mathrm{m})$, then the full value of $K\left(\mathrm{PI} / \mathrm{PI}_{*}\right)^{6}$ is used at $50 \mathrm{~m}$, and the diffusion applied at the $120-\mathrm{m}$ interface is adjusted accordingly.

We ran two experiments with the interactive mixing: one to replicate the present climate and another with 10 times the present amount of $\mathrm{CO}_{2}$. The circulations are shown in Fig. 7. The simulation with 338-ppm $\mathrm{CO}_{2}$ is largely similar to the control run with constant mixing (Figs. 1a,b); the additional mixing from the parameterization of tropical cyclone mixing contributes to a slight increase in the intensity of the surface Ekman cells and a $0.9-\mathrm{Sv}$ increase in the meridional overturning circulation. But in the experiment with 3380-ppm $\mathrm{CO}_{2}$, SSTs 
(a)
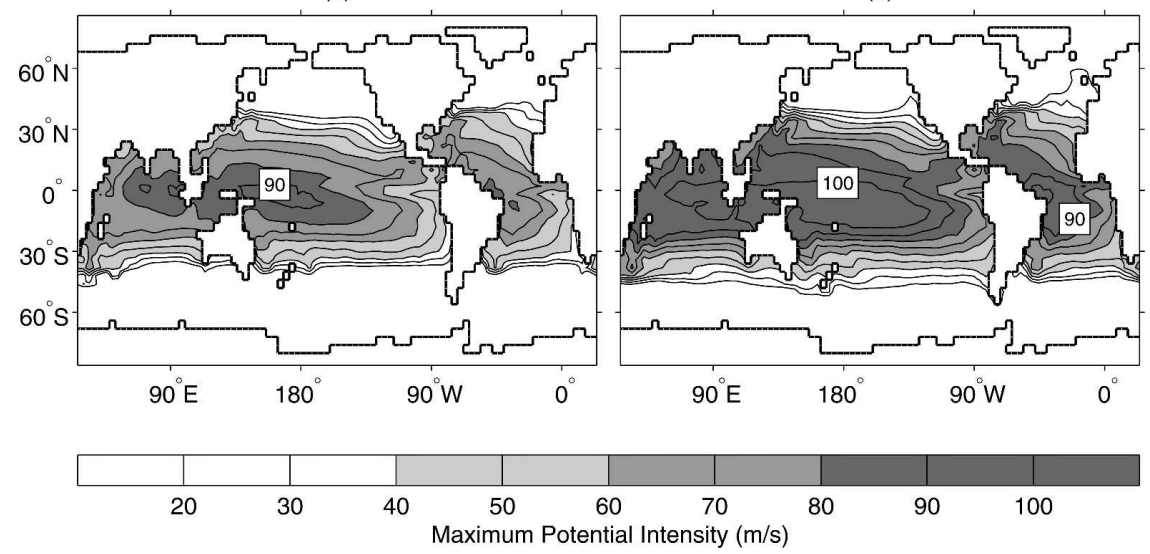

FIG. 8. The annually averaged PI of tropical cyclones in (a) a simulation with interactive mixing and 338-ppm $\mathrm{CO}_{2}$ and (b) a simulation with interactive mixing and 3380-ppm $\mathrm{CO}_{2}$. are considerably warmer (not shown), and the potential intensity increases (Fig. 8), which leads to stronger mixing through (8). Throughout the tropics, PI values are $10 \%$ (near the equator) to $40 \%$ (at the subtropical edge) higher in Fig. $8 \mathrm{~b}$ than in Fig. 8a; note the rapid transition to small PI values in the subtropics of both simulations. The increases in PI force the values of $\kappa$, via (8), to be substantially higher in the warm climate than in the present one. Figures 9a,c,e show the total value of $\kappa$ in both the present climate and Figs. 9b,d,f (a) $\kappa$ at $50 \mathrm{~m}$ when $\mathrm{CO}_{2}$ is $338 \mathrm{ppm}$

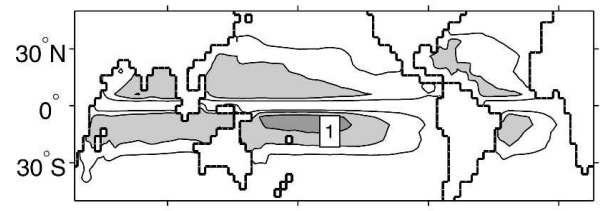

(c) $\kappa$ at $120 \mathrm{~m}$ when $\mathrm{CO}_{2}$ is $338 \mathrm{ppm}$

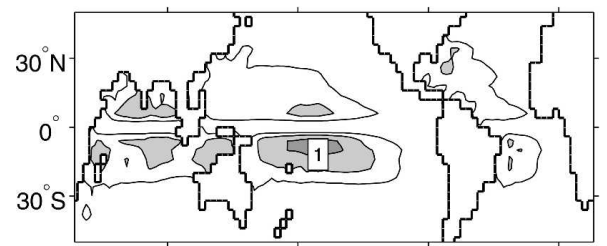

(e) $\kappa$ at $220 \mathrm{~m}$ when $\mathrm{CO}_{2}$ is $338 \mathrm{ppm}$

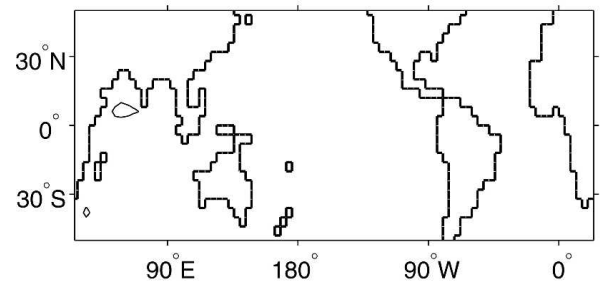

(b) $\kappa$ at $50 \mathrm{~m}$ when $\mathrm{CO}_{2}$ is $3380 \mathrm{ppm}$

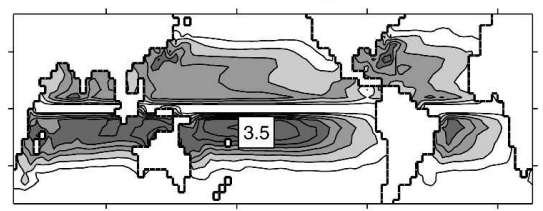

(d) $\kappa$ at $120 \mathrm{~m}$ when $\mathrm{CO}_{2}$ is $3380 \mathrm{ppm}$

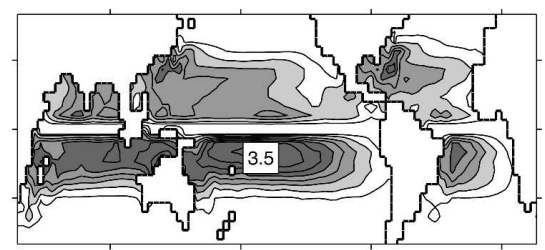

(f) $\kappa$ at $220 \mathrm{~m}$ when $\mathrm{CO}_{2}$ is $3380 \mathrm{ppm}$

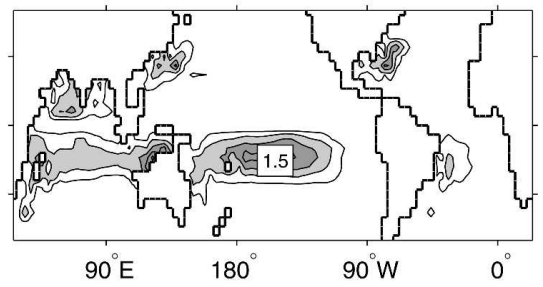

FIG. 9. The total value of $\kappa$ (i.e., $\kappa_{b}+\kappa_{s}$ ) for (a), (c), (e) a simulation with interactive mixing and 338-ppm $\mathrm{CO}_{2}$ and (b), (d), (f) a simulation with interactive mixing and 3380-ppm $\mathrm{CO}_{2}$. Values are shown at (top) 50-, (middle) 120-, and (bottom) 220-m depth. 
(a)

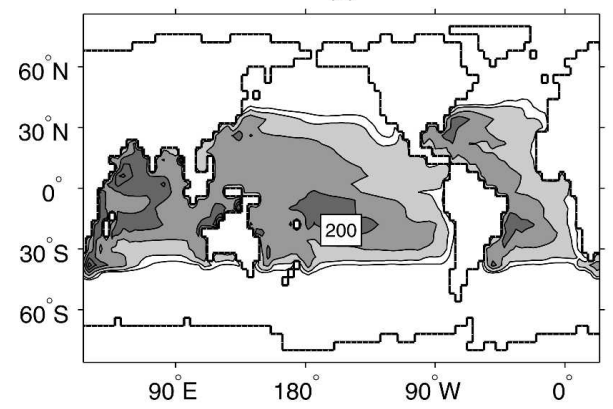

(b)

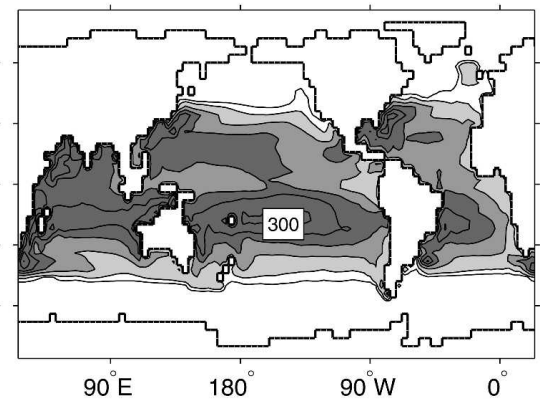

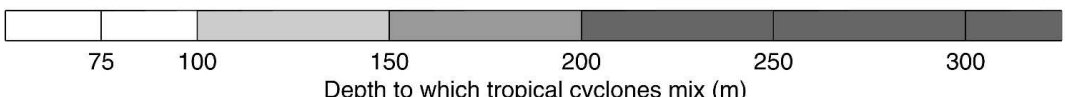

FIG. 10. Depth to which $\kappa_{s}$ is added for (a) the present-day climate and (b) high $\mathrm{CO}_{2}$ climate.

in one with 3380-ppm $\mathrm{CO}_{2}$ applied at the (top) 50-, (middle) 120-, and (bottom) 220-m model layer interfaces. In addition to substantially stronger values of the diffusion coefficient, the higher values of PI in the warmer climate also allow the storm mixing to penetrate more deeply. The depths computed by (7) are shown in Fig. 10. In the present climate (Fig. 10a), the total depth has been scaled by $h_{*}$ in (7) (see the appendix), so that values of $h_{o}+\Delta h$ are between 100 and 200 $\mathrm{m}$ through most of the tropics. ${ }^{9}$ The combination of stronger mixing from (8) and its concomitant weakening of the stratification of the upper ocean produce deeper mixing in the warmer climate (Fig. 10b). The mixing depths exceed $150 \mathrm{~m}$ throughout the tropics, with many areas experiencing elevated mixing below $200 \mathrm{~m}$. The maximum increase over the present climate occurs between $10^{\circ}$ and $25^{\circ} \mathrm{S}$ in the Pacific, where values have increased by as much as $110 \mathrm{~m}$. By applying strong mixing below the initial mixed layer depth, $\kappa_{s}$ weakens the stratification of the upper ocean by mixing heat down the water column. The heat content of the tropical oceans between 50 and $360 \mathrm{~m}$ is higher in these simulations than when only a uniformly weak diffusion coefficient was applied; Pasquero and Emanuel (2008) found a similar result.

The strong mixing of the upper tropical oceans cools the areas where $\kappa_{s}$ is nonzero and warms the middle latitudes. Figure 11 shows the SST difference between the high $\mathrm{CO}_{2}$ simulation using the tropical cyclone parameterization and the high $\mathrm{CO}_{2}$ simulation using uni-

\footnotetext{
${ }^{9}$ Although (7) is computed everywhere (including the equator), the value of $\kappa_{s}$ that is added to this depth will be 0 wherever dictated by (8).
}

formly weak mixing (discussed in section 3). Most of the tropics have cooled slightly (except along the equator where the interactive mixing parameterization is not applied), while middle latitudes, particularly along the continental margins, have warmed. Figure $11 \mathrm{~b}$ shows the change in zonal-mean SSTs between these two runs and indicates that the subtropical temperature gradient has weakened slightly. These differences are supported by a change in the ocean heat flux, which is shown in Fig. 12. When mixing was uniformly weak, the ocean heat flux decreased when $\mathrm{CO}_{2}$ was increased (see Fig. 2 ). In the simulation using the tropical cyclone parameterization, the ocean heat fluxes are stronger in the (a)

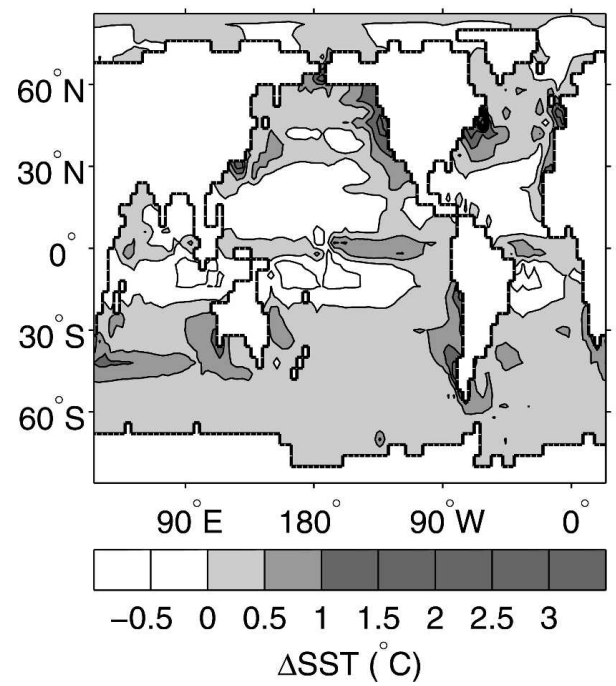

(b)

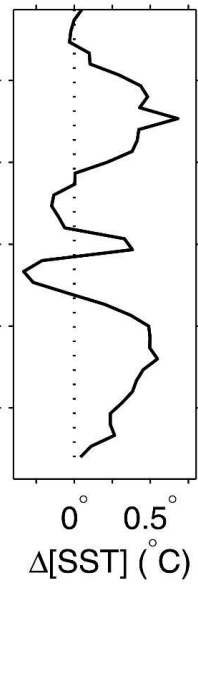

FIG. 11. (a) Changes in SST between a simulation with interactive mixing and the control with uniformly weak mixing; both were forced with 3380-ppm $\mathrm{CO}_{2}$. (b) Zonally averaged change in SST. 


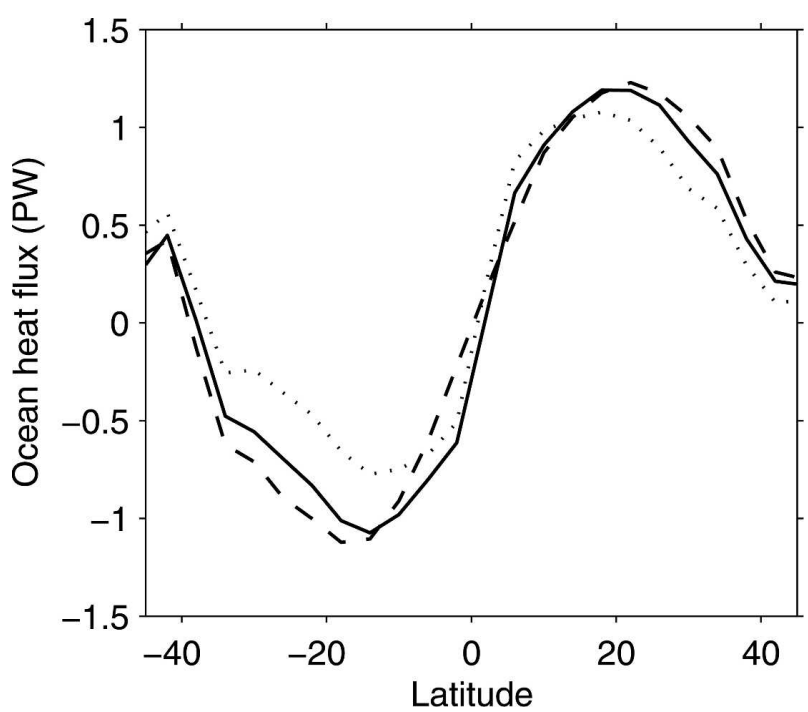

FIG. 12. As in Fig. 2 but for runs with interactive mixing and 338-ppm $\mathrm{CO}_{2}$ (solid), interactive mixing and 3380-ppm $\mathrm{CO}_{2}$ (dashed), and uniformly weak mixing and 3380-ppm $\mathrm{CO}_{2}$ (dotted).

present climate than in the control, but, unlike before, the peak values increase as the climate warms. The peak values increase by $3 \%$ in the Northern Hemisphere and $5 \%$ in the Southern Hemisphere relative to the present-day simulation. Relative to the high $\mathrm{CO}_{2}$ simulation with uniformly weak mixing (dotted line in Fig. 12), the peak values are $14 \%$ higher in the Northern Hemisphere and $45 \%$ larger in the Southern Hemisphere. Clearly including a representation of tropical cyclones can have a large effect, and it can affect how the ocean heat flux responds to changes in radiative forcing.

\section{Discussion and conclusions}

We have demonstrated that a coupling between tropical cyclone mixing and radiative forcing can increase the oceans' heat transport during warm, equable climates. This differs from simulations with uniformly weak mixing, where the ocean heat flux decreased in intensity when the surface density gradient decreased. We have also shown that even in the present climate, transient events are likely as important as background processes to the mixing that occurs in the upper tropical oceans. Given that models are highly sensitive to mixing in the tropics (Scott and Marotzke 2002; Bugnion et al. 2006), some interesting behavior emerges when mixing in these locations evolves with climate. Our control simulation produces ocean heat fluxes for the present climate (see Fig. 2) weaker than many observational studies (see Ganachaud and Wunsch 2000, and refer- ences therein), which is often a deficiency of coarseresolution models (e.g., Opsteegh et al. 1998; Goosse et al. 2001). It would be worth repeating these experiments in a higher-resolution model to see if the magnitude of changes in the ocean heat fluxes is sensitive to resolution, but this lies beyond the scope of our present work.

The parameterization that we implemented to represent mixing from tropical cyclones introduces a new coupling between the ocean and climate. We leave it to future work to examine the sensitivity to the precise formulation, but there are several mechanisms that could amplify the response beyond what we have presented here. Ekman pumping, which can enhance mixing in slowly moving or stationary storms (Price 1981), scales with the wind stress and could affect the mixing depth. The internal wave field is an important energy source for interior mixing (Munk and Wunsch 1998) and tropical cyclones contribute energy to it (Nilsson 1995). Enhanced mixing from tropical cyclones could also be accompanied by stronger interior mixing through the stratification feedback discussed by Lyle (1997) and Nilsson et al. (2003). For example, if in a warmer climate the atmospheric latent heat flux increased and weakened upper-ocean subtropical salinity gradients, $\kappa_{b}$ could grow (cf. Nilsson et al. 2003) and $\kappa_{s}$ could be relevant at greater depth [via (7)].

Another complexity arises when actual storm intensities are used in place of PI. We implicitly assumed that the ratio between actual intensity and PI is constant across climate, but the ocean's negative feedback on storm intensity (Schade and Emanuel 1999) could be weaker in equable climates if subsurface ocean temperatures increase strongly (cf. Pasquero and Emanuel 2008). To illustrate this point, we used the coupled hurricane-ocean model described by Schade and Emanuel (1999) to compare the mixed layer depth in a storm's wake when the stratification varies. The atmospheric component of this model is described by Emanuel (1995) and is constructed on the assumption that the storm is axisymmetric, in hydrostatic and gradient wind balance, and that the vortex is always near a state of neutral stability with respect to slantwise convection. It is coupled to a three-dimensional-layer ocean model adapted from the work of Cooper and Thompson (1989). Figure 13a shows results for a simulation of a storm translating west at $5 \mathrm{~m} \mathrm{~s}^{-1}$ using a typical upperocean structure for the present climate [the initial thermal structure includes a SST and mixed layer (50-m depth) temperature of $30^{\circ} \mathrm{C}$ with a linear decrease to $14^{\circ} \mathrm{C}$ by $350 \mathrm{~m}$ below]. As momentum is deposited in the surface layer, a shear builds on the base of the 

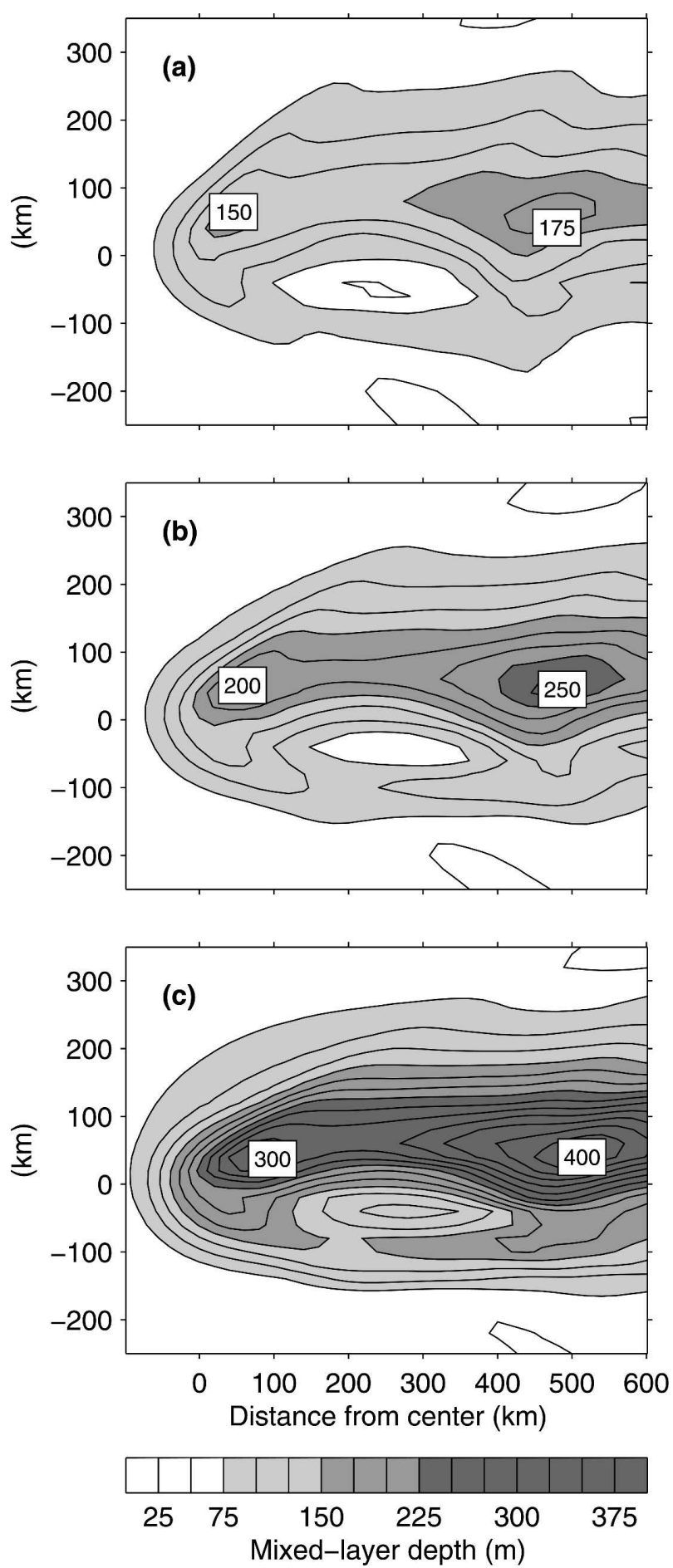

FIG. 13. The mixed layer depth following the passage of a tropical cyclone when the mixed layer temperature is initially $30^{\circ} \mathrm{C}$ and the temperature at $350 \mathrm{~m}$ decreased to (a) $14^{\circ}$, (b) $22^{\circ}$, and (c) $28^{\circ} \mathrm{C}$.

mixed layer, lowering the local Richardson number to its critical value. Turbulent entrainment ensues and the mixed layer depth increases $\sim 100 \mathrm{~m}$ to the right of the storm's center, where the response is strongest; oscilla- tions at depth continue in the storm's wake from inertia-gravity waves (Price 1981). For the simulation shown in Fig. 13b, we made a single change: the temperature at $350-\mathrm{m}$ depth was raised to $22^{\circ} \mathrm{C}$. With the mixed layer temperature fixed at $30^{\circ} \mathrm{C}$, this has the sole effect of weakening thermocline stratification by about a factor of 2. Figure 13c shows results when the 350-m temperature is raised to $28^{\circ} \mathrm{C}$. The storm is now able to mix deeper in Figs. 13b and 13c: mixed layer depths along and to the right of the track increase by $50-75 \mathrm{~m}$ in Fig. 13b and by more than $100 \mathrm{~m}$ in Fig. 13c relative to Fig. 13a, indicating that mixing has penetrated deeper into the thermocline. The magnitude of the response is somewhat larger than predicted by (7) because there is a positive feedback at work in this model: the water entrained into the surface layer is warmer when the stratification is weaker, which lessens the cooling of SSTs below the storm's core. This allows stronger air-sea fluxes into the cyclone, creating a stronger storm. This in turn means the surface stress on the ocean's surface is enhanced and leads to a greater deposition of momentum in the upper ocean. This feedback between $u$ and $\Gamma$ is not considered in (7) when PI is used to represent intensity.

Tropical cyclones could amplify upper-ocean mixing in low latitudes when radiative forcing increases greatly. The penetration depth of this mixing increases too, but the changes are a function of the stratification as well. Future work is required to elucidate the sensitivity of this mechanism to model resolution and ocean structure. Further knowledge about how the cold wakes of tropical cyclones recover is also needed. For example, if the heating in the wake of a storm were confined to a shallow layer, the remaining cold anomaly would be isolated from the surface, reducing the column heating applied from the atmosphere. Emanuel (2001) provided some evidence that the net column heating may extend through the full depth of the prestorm mixed layer, but direct measurements are needed to better quantify the process. Resolution of these issues lies beyond the scope of this conceptual paper. Our main conclusion is that interactive mixing in the upper ocean, whatever its source, can change the way in which the ocean heat flux responds. Paleoclimate studies should be aware of these possibilities.

Acknowledgments. We thank Peter Stone for many invaluable conversations and thoughtful suggestions regarding this work. Matthew Huber, Johan Nilsson, and an anonymous reviewer provided very helpful comments on an earlier version of this manuscript. The National Science Foundation (Grant ATM-0001039) provided support for this research. 


\section{APPENDIX}

\section{Estimate of Mixing Depth}

Changes in SST are directly related to the depth mixing penetrates. For simplicity, we take $d \rho / d z(\Gamma)$ to be linear below the mixed layer, as illustrated in Fig. 5; it follows that the initial, vertically averaged density in the region between $h_{o}$ and $h_{f}$ is

$$
\overline{\rho_{i}}\left(h_{o} \rightarrow h_{f}\right)=\rho_{o}-\frac{\Gamma \Delta h}{2},
$$

which is equal to the initial density evaluated at $h_{o}+\Delta h / 2$. The final density is the weighted average of the initial mixed layer density and the density given by (A1), such that

$$
\rho_{f}=\frac{\rho_{o} h_{o}+\left(\rho_{o}-\frac{1}{2} \Gamma \Delta h\right) \Delta h}{h_{o}+\Delta h} .
$$

Writing $\rho_{f}$ as $\rho_{o}-\Delta \rho$ yields an expression relating the degree of surface density changes (principally from a drop in SSTs) to the penetration depth of the turbulent mixing:

$$
\Delta \rho=\frac{\Gamma}{2} \frac{(\Delta h)^{2}}{h_{o}+\Delta h} .
$$

This depth is directly related to the rate of entrainment $w_{e}$ :

$$
\int_{h_{o}}^{h_{f}} d h=\int_{0}^{\tau} w_{e} d t ;
$$

$\tau$ is the duration of the intense mixing. There is an extensive literature devoted to parameterizations of entrainment and turbulent mixing; the formulation developed by Price (1979), Thompson (1979), and Kranenburg (1984) has been used successfully in coupled hurricane-ocean models (Schade and Emanuel 1999; Emanuel et al. 2004). The fundamental premise behind the mixing closure developed by Price (1979) is the constancy of the bulk Richardson number, which is defined as

$$
R_{b *}=\frac{g \Delta \rho h}{\rho_{o} u_{*}^{2}},
$$

where $u_{*}^{2}$ is the square of the friction velocity and $h$ is the mixed layer depth. These authors found that the ratio $w_{e} / u_{*}$ is proportional to the square root of the inverse of the bulk Richardson; it follows that

$$
w_{e}=\frac{n u_{*}^{2}}{\sqrt{g h \alpha \delta \rho}},
$$

where $n$ is a constant of proportionality and $\alpha$ is the specific volume.

The jump in density across the base of the surface layer $\delta \rho$ evolves with time, but for any depth $h$, the density approaching this depth from above will be $\rho\left(h^{+}\right)=\rho_{\mathrm{ml}}$, which is the adjusted density of the mixed layer (the change in mixed layer density from entrainment is assumed to be instantaneous); the density approaching $h$ from below is equal to the initial density at this level, $\rho\left(h^{-}\right)=\rho_{o}-\Gamma\left(h-h_{o}\right)$. Taking the difference yields

$$
\delta \rho=\rho_{\mathrm{ml}}-\rho_{o}+\Gamma\left(h-h_{o}\right) .
$$

Making the simplification of representing $w_{e}$ with a temporal average, (A4) yields

$$
\Delta h=\overline{w_{e}} \tau .
$$

Note from (A6) that the rate of entrainment will decrease when the mixed layer is deeper and the jump in density across its base increases. As the mixed layer deepens, the surface stress goes into currents over a greater depth, lessening the shear across the base of the mixed layer; as the density jump increases, it takes a more powerful shear to overcome the resistance given by the jump in stratification.

To estimate $\overline{w_{e}}$, we set the temporal average of the entrainment velocity equal to its smallest value: this occurs as the mixed layer reaches $h_{f}$, just prior to the cessation of mixing when the density jump is largest. With this choice, it follows from (A6) that

$$
w_{e}^{2}=\frac{n^{2} u_{*}^{4}}{g \alpha h_{f} \delta \rho} ;
$$

from (A7), $\delta \rho$ is

$$
\delta \rho=-\Delta \rho+\Gamma\left(h_{f}-h_{o}\right)
$$

at its maximum $\left(\rho_{\mathrm{ml}}=\rho_{f}\right)$. Using (A3), (A9), and (A10) in (A8) yields

$$
(\Delta h)^{4}+2 h_{o}(\Delta h)^{3}=\frac{2 n^{2} \tau^{2} u_{*}^{4}}{g \alpha \Gamma} .
$$

A good estimate of the behavior of this quartic equation is

$$
\Delta h=h_{*}\left(\frac{u}{u_{*}}\right)^{1.2}\left(\frac{\Gamma}{\Gamma_{*}}\right)^{-0.3}
$$

over realistic parameter ranges. The mixing penetration depth will increase nearly linearly with the strength of the storm; weaker stratification in the thermocline will also increase the penetration depth, though this effect is 
smaller. We choose $h_{*}$ to be $100 \mathrm{~m}$, a typical value observed in the present climate (e.g., Price 1981; see also Fig. 13a). As we are using potential intensity as the measure of tropical cyclone activity, $u_{*}$ is taken to be $65 \mathrm{~m} \mathrm{~s}^{-1}$, an average value found in the present climate (see Fig. 8a). The value of $N$ in the upper tropical oceans is approximately $0.02 \mathrm{~s}^{-1}$ (Gill 1982, p. 52), and this is used to calculate $\Gamma_{*}$.

\section{REFERENCES}

Abbot, D. S., and E. Tziperman, 2008: Sea ice, high latitude convection, and equable climates. Geophys. Res. Lett., in press.

Barron, E. J., 1983: A warm, equable Cretaceous: The nature of the problem. Earth Sci. Rev., 19, 305-338.

— High atmospheric $\mathrm{CO}_{2}$ as a plausible mechanism. The Carbon Cycle and Atmospheric $\mathrm{CO}_{2}$ : Natural Variations Archean to Present, Geophys. Monogr., Vol. 32, Amer. Geophys. Union, 546-553.

Boccaletti, G., R. Ferrari, A. Adcroft, D. Ferreira, and J. Marshall, 2005: The vertical structure of ocean heat transport. Geophys. Res. Lett., 32, L10603, doi:10.1029/2005GL022474.

Boos, W. R., J. R. Scott, and K. A. Emanuel, 2004: Transient diapycnal mixing and the meridional overturning circulation. $J$. Phys. Oceanogr., 34, 334-341.

Bugnion, V., C. Hill, and P. H. Stone, 2006: An adjoint analysis of the meridional overturning circulation in a hybrid coupled model. J. Climate, 19, 3751-3767.

Collins, W. D., and Coauthors, 2006: The Community Climate System Model version 3 (CCSM3). J. Climate, 19, 2122-2143.

Cooper, C., and J. D. Thompson, 1989: Hurricane-generated currents on the outer continental shelf. 2. Model sensitivity studies. J. Geophys. Res., 94, 12 540-12 554.

Crowley, T. J., 2000: Carbon dioxide and Phanerozoic climate: An overview. Warm Climates in Earth History, B. T. Huber, K. G. MacLeod, and S. L. Wing, Eds., Cambridge University Press, 425-444.

Cummins, P. F., G. Holloway, and A. E. Gargett, 1990: Sensitivity of the GFDL ocean general circulation model to a parameterization of vertical diffusion. J. Phys. Oceanogr., 20, 817830.

Dawson, M. R., R. M. West, W. Langston, and J. H. Hutchinson, 1976: Paleogene terrestrial vertebrates: Northernmost occurrence, Ellesmere Island, Canada. Science, 192, 781-782.

Dutkiewicz, S., A. Sokolov, J. Scott, and P. Stone, 2005: A threedimensional ocean-sea-ice-carbon cycle model and its coupling to a two-dimensional atmospheric model: Uses in climate change studies. Joint Program on the Science and Policy of Global Change, Massachusetts Institute of Technology Tech. Rep. 122, 47 pp.

Eberle, J. J., and J. E. Storer, 1999: Northernmost record of brontotheres, Axel Heiberg Island, Canada-Implications for age of the Buchanan Lake formation and brontothere paleobiology. J. Paleontol., 73, 979-983.

Emanuel, K. A., 1988: The maximum intensity of hurricanes. $J$. Atmos. Sci., 45, 1143-1155.

-, 1995: The behavior of a simple hurricane model using a convective scheme based on subcloud-layer entropy equilibrium. J. Atmos. Sci., 52, 3959-3968.
_ 2000: A statistical analysis of hurricane intensity. Mon. Wea. Rev., 128, 1139-1152.

_ 2001: Contribution of tropical cyclones to meridional heat transport by the oceans. J. Geophys. Res., 106, 14 771-14 782. , 2002: A simple model of multiple climate regimes. J. Geophys. Res., 107, 4077, doi:10.1029/2001JD001002.

- 2005: Increasing destructiveness of tropical cyclones over the past 30 years. Nature, 436, 686-688.

- , and D. S. Nolan, 2004: Tropical cyclone activity and the global climate system. Preprints, 26th Conf. on Hurricanes and Tropical Meteorology, Miami, FL, Amer. Meteor. Soc., 240-241.

— C. DesAutels, C. Holloway, and R. Korty, 2004: Environmental control of tropical cyclone intensity. J. Atmos. Sci., 61, 843-858.

Ganachaud, A., and C. Wunsch, 2000: Improved estimates of global ocean circulation, heat transport and mixing from hydrographic data. Nature, 408, 453-457.

Gill, A. E., 1982: Atmosphere-Ocean Dynamics. Academic Press, $662 \mathrm{pp}$.

Goosse, H., F. M. Selten, R. J. Haarsma, and J. D. Opsteegh, 2001: Decadal variability in high northern latitudes as simulated by an intermediate-complexity climate model. Ann. Glaciol., 33, 525-532.

Gray, W. M., 1968: Global view of tropical disturbances and storms. Mon. Wea. Rev., 96, 669-700.

Gregg, M. C., 1987: Diapycnal mixing in the thermocline: A review. J. Geophys. Res., 92, 5249-5286.

Gregory, J. M., and Coauthors, 2005: A model intercomparison of changes in the Atlantic thermohaline circulation in response to increasing atmospheric $\mathrm{CO}_{2}$ concentration. Geophys. Res. Lett., 32, L12703, doi:10.1029/2005GL023209.

Haidvogel, D. B., and F. G. Bryan, 1992: Ocean general circulation modeling. Climate System Modeling, K. E. Trenberth, Ed., Cambridge University Press, 371-412.

Huber, B. T., K. G. MacLeod, and S. L. Wing, Eds., 2000: Warm Climates in Earth History. Cambridge University Press, $462 \mathrm{pp}$.

Kamenkovich, I. V., A. P. Sokolov, and P. H. Stone, 2002: An efficient climate model with a $3 \mathrm{D}$ ocean and statisticaldynamical atmosphere. Climate Dyn., 19, 585-598.

Kirk-Davidoff, D. B., D. P. Schrag, and J. G. Anderson, 2002: On the feedback of stratospheric clouds on polar climate. Geophys. Res. Lett., 29, 1556, doi:10.1029/2002GL014659.

Korty, R. L., 2005: On the maintenance of weak meridional temperature gradients during warm climates. Ph.D. thesis, Massachusetts Institute of Technology, $248 \mathrm{pp}$.

Kranenburg, C., 1984: Wind-induced entrainment in a stably stratified fluid. J. Fluid Mech., 145, 253-273.

Ledwell, J. R., A. J. Watson, and C. S. Law, 1998: Mixing of a tracer in the pycnocline. J. Geophys. Res., 103, 21 499-21 529.

— , E. T. Montgomery, K. L. Polzin, L. C. St. Laurent, R. W. Schmitt, and J. M. Toole, 2000: Evidence for enhanced mixing over rough topography in the abyssal ocean. Nature, 403, 179-182.

Leipper, D., 1967: Observed ocean conditions and Hurricane Hilda, 1964. J. Atmos. Sci., 24, 182-186.

Luyten, J., J. Pedlosky, and H. Stommel, 1983: The ventilated thermocline. J. Phys. Oceanogr., 13, 292-309.

Lyle, M., 1997: Could early Cenozoic thermohaline circulation have warmed the poles? Paleoceanography, 12, 161-167.

Marshall, J., C. Hill, L. Perelman, and A. Adcroft, 1997a: Hydro- 
static, quasi-hydrostatic, and nonhydrostatic ocean modeling. J. Geophys. Res., 102, 5733-5752.

— A. Adcroft, C. Hill, L. Perelman, and C. Heisey, 1997b: A finite-volume, incompressible Navier Stokes model for studies of the ocean on parallel computers. J. Geophys. Res., 102, $5753-5766$.

McKenna, M., 1980: Eocene paleolatitude, climate, and mammals of Ellesmere Island. Palaeogeogr. Palaeoclimatol. Palaeoecol., 30, 349-362.

Munk, W., and C. Wunsch, 1998: Abyssal recipes II: Energetics of tidal and wind mixing. Deep-Sea Res., 45, 1977-2010.

Nilsson, J., 1995: Energy flux from traveling hurricanes to the oceanic internal wave field. J. Phys. Oceanogr., 25, 558-573.

—, G. Broström, and G. Walin, 2003: The thermohaline circulation and vertical mixing: Does weaker density stratification give stronger overturning? J. Phys. Oceanogr., 33, 2781-2795.

Opsteegh, J. D., R. J. Haarsma, F. M. Selten, and A. Kattenberg, 1998: ECBILT: A dynamic alternative to mixed boundary conditions in ocean models. Tellus, 50A, 348-367.

Pasquero, C., and K. Emanuel, 2008: Tropical cyclones and transient upper-ocean warming. J. Climate, 21, 149-162.

Pearson, P. N., P. W. Ditchfield, J. Singano, K. G. HarcourtBrown, C. J. Nicholas, R. K. Olsson, N. J. Shackleton, and M. A. Hall, 2001: Warm tropical sea surface temperatures in the Late Cretaceous and Eocene epochs. Nature, 413, 481487.

Price, J. F., 1979: On the scaling of stress-driven entrainment experiments. J. Fluid Mech., 90, 509-529.

_- 1981: Upper ocean response to a hurricane. J. Phys. Oceanogr., 11, 153-175.

_- 1983: Internal wave wake of a moving storm. Part I: Scales, energy budget, and observations. J. Phys. Oceanogr., 13, 949965.

— Geophys. Res., 104, 20 467-20 494.

Raymond, D. J., and Coauthors, 2004: EPIC2001 and the coupled ocean-atmosphere system of the tropical east Pacific. Bull. Amer. Meteor. Soc., 85, 1341-1354.

Schade, L. R., 1994: The ocean's effect on hurricane intensity. Ph.D. thesis, Massachusetts Institute of Technology, 125 pp.

_ and K. A. Emanuel, 1999: The ocean's effect on the intensity of tropical cyclones: Results from a simple coupled atmosphere-ocean model. J. Atmos. Sci., 56, 642-651.

Schweitzer, H. J., 1980: Environment and climate in the early Tertiary of Spitsbergen. Palaeogeogr. Palaeoclimatol. Palaeoecol., 30, 297-311.

Scott, J. R., and J. Marotzke, 2002: The location of diapycnal mixing and the meridional overturning circulation. J. Phys. Oceanogr., 32, 3328-3345.
Shellito, C. J., L. C. Sloan, and M. Huber, 2003: Climate model sensitivity to atmospheric $\mathrm{CO}_{2}$ levels in the early-middle Paleogene. Palaeogeogr. Palaeoclimatol. Palaeoecol., 193, 113123.

Sloan, L. C., and D. K. Rea, 1996: Atmospheric carbon dioxide and early Eocene climate: A general circulation modeling sensitivity study. Palaeogeogr. Palaeoclimatol. Palaeoecol., 119, 275-292.

_ J. C. G. Walker, T. C. Moore Jr., D. K. Rea, and J. C. Zachos, 1992: Possible methane-induced polar warming in the early Eocene. Nature, 357, 320-322.

Sluijs, A., and Coauthors, 2006: Subtropical Arctic Ocean temperatures during the Palaeocene/Eocene thermal maximum. Nature, 441, 610-613.

Sokolov, A., and P. Stone, 1998: A flexible climate model for use in integrated assessments. Climate Dyn., 14, 291-303.

Sriver, R. L., and M. Huber, 2007: Observational evidence for an ocean heat pump induced by tropical cyclones. Nature, 447, 577-580.

Stone, P. H., and D. Miller, 1980: Empirical relations between seasonal changes in meridional temperature gradients and meridional fluxes of heat. J. Atmos. Sci., 37, 1708-1721.

—, and M.-S. Yao, 1987: Development of a two-dimensional zonally averaged statistical-dynamical model. Part II: The role of eddy momentum fluxes in the general circulation and their parameterization. J. Atmos. Sci., 44, 3769-3786.

_ , and _ 1990: Development of a two-dimensional zonally averaged statistical-dynamical model. Part III: The parameterization of the eddy fluxes of heat and moisture. $\mathrm{J}$. Climate, 3, 726-740.

Stouffer, R. J., and S. Manabe, 2003: Equilibrium response of thermohaline circulation to large changes in atmospheric $\mathrm{CO}_{2}$ concentration. Climate Dyn., 20, 759-773.

Thompson, R., 1979: A reinterpretation of the entrainment process in some laboratory experiments. J. Fluid Mech., 46, 299319.

Tripati, A. K., M. L. Delaney, J. C. Zachos, L. D. Anderson, D. C. Kelly, and H. Elderfield, 2003: Tropical sea-surface temperature reconstruction for the early Paleogene using $\mathrm{Mg} / \mathrm{Ca}$ ratios of planktonic foraminifera. Paleoceanography, 18, 1101, doi:10.1029/2003PA000937.

Wiebe, E. C., and A. J. Weaver, 1999: On the sensitivity of global warming experiments to the parameterisation of sub-grid scale ocean mixing. Climate Dyn., 15, 875-893.

Wunsch, C., and R. Ferrari, 2004: Vertical mixing, energy, and the general circulation of the oceans. Annu. Rev. Fluid Mech., 36, 281-314. 